\title{
RESENHA
}

\section{Quando o negacionismo vai a júri: um filme sobre liberdade de expressão e agressão à democracia}

\author{
When the denial goes to court: a movie on freedom of \\ expression and assault on democracy
}

\section{Piergiuseppe Parisi* Laíze Gabriela Benevides Pinheiro**}

Quando a oportunidade de escrever uma resenha sobre Negação (Denial) (2016) para esta revista se apresentou, perguntei-me qual seria a relevância desse filme no contexto específico do Brasil hoje. Além disso, compartilhar esse espaço com um colega que esteve na vanguarda dos protestos sociais que encheram as ruas do Rio de Janeiro levantou uma discussão sobre minha perspectiva eurocêntrica ${ }^{1}$.

No continente europeu, onde recebi a maior parte das minhas instruções, o caso David Irving versus Penguin Books e Deborah Lipstadt, sobre o qual o filme é inspirado, teve relevância fundamental, como testemunhado pela tradução francesa do título do filme, Le Procès du siècle (literalmente "O processo do século" em português). Nas últimas décadas, assistimos a um debate florescente na Europa sobre a regulamentação da memória pelo Estado e o papel dos tribunais no julgamento de casos de negacionismo². É claro que George Orwell, em 1984, sublinhou a importância do assunto: "Quem controla o presente controla o passado e quem controla o passado controlará o futuro".

Se, por um lado, essas palavras nos alertam sobre os riscos de atribuir poder regulatório ao Estado em questões de memória, o contexto atual na Europa e no Brasil, assim como em muitas outras partes do mundo, nos confronta com o conteúdo e os limites de liberdade de expressão. Isso é bem resumido pela protagonista do filme, Deborah E. Lipstadt (interpretada por Rachel Weisz), na coletiva de imprensa final, quando ela declara:

\footnotetext{
* Pesquisador associado ao Centro de Direitos Humanos Aplicados da Universidade de York (Reino Unido); Doutor em Estudos Internacionais pela Universidade de Trento (Itália) e mestre em Direito pela mesma universidade; Mestre em Direito pela Universidade London South Bank (Reino Unido). E-mail: piergiuseppe.parisi@york.ac.uk

** Doutoranda em Direito na UFRJ; Mestra em Direito Constitucional pela UFF; Bacharela em Direito pela UFS. Advogada Popular. E-mail: ize.benevides@gmail.com

1 Esta resenha foi redigida a quatro mãos. A primeira parte, onde se reconstrói o marco teórico a partir de uma perspectiva majoritariamente europeia, foi redigida por Piergiuseppe Parisi italiano residente do Reino Unido. A segunda parte, que contextualiza o tema no Brasil das últimas décadas, por Laíze Benevides, brasileira.

2 Uladzislau Belavusau e Aleksandra Gliszczyńska-Grabias, 'The Remarkable Rise of "Law and Historical Memory" in Europe: Theorizing Trends and Prospects in the Recent Literature' (2020) 47(2) Journal of Law and Society 325-338; Emanuela Fronza, Memory and Punishment: Historical Denialism, Free Speech and the Limits of Criminal Law (Asser Press 2018); Uladzislau Belavusau e Aleksandra Gliszczyńska-Grabias (eds), Law and Memory: Towards Legal Governance of History (Cambridge University Press 2017); Valentina Pisanty, 'Negare e punire: It takes two to tango' (2017) XXXIII(125) Notizie di Politeia 64-77; Eric Heinze, 'Theorizing Law and Historical Memory: Denialism and the Pre-conditions of Human Rights' (2018) 13(1) The Journal of Comparative Law 43-60.
} 
"Eu não ataquei a liberdade de expressão, pelo contrário. Eu a defendi contra alguém que queria abusar dela. A liberdade de expressão significa que podemos dizer o que quisermos, o que não se pode fazer é mentir e depois não arcar com as consequências disso. Nem todas as opiniões são iguais".

Sem dúvida, a última década foi caracterizada por uma instrumentalização da memória histórica com fins políticos evidentes por meio de uma representação parcial ou até distorcida da história.

O filme enfoca o processo de difamação apresentado pelo escritor britânico David Irving contra Deborah E. Lipstadt, historiadora americana e autora do livro The Holocaust Denial (A Negação do Holocausto) - no qual a autora caracterizou algumas das declarações de Irving como negacionistas do Holocausto - e sua editora Penguin Books.

Os riscos colocados pelo conflito entre a liberdade de expressão e a dignidade dos sobreviventes permeiam todo o filme. Uma decisão a favor de Irving significaria que suas alegações negacionistas não eram negacionistas ou que, como o juiz do caso coloca no final do processo, as posições negacionistas de Irving não podem ser consideradas ilegítimas, pois o autor acredita intimamente nelas. Ambos os casos representariam um desastre.

No primeiro caso, a falta de provas judiciais suficientes sobre a existência de câmaras de gás equivaleria a afirmar que elas nunca existiram do ponto de vista do direito processual. Porém, como sabemos, as regras processuais destinadas a estabelecer uma verdade judicial firme, não passível de revisão ou recurso, por razões de estabilidade do sistema jurídico e certeza das relações jurídicas ${ }^{3}$, diferem profundamente do método histórico (FRONZA e GAMBERINI, 2013, p.5). Este é intrinsecamente revisionista, pois novas evidências históricas podem surgir a qualquer momento pondo em discussão fatos que até o momento eram considerados esclarecidos ${ }^{4}$ (VIDAL-NAQUET, 2007).

No segundo caso, seria admitido que a liberdade de expressão não tem limites, basta dizer que o autor de posições subversivas acredita intimamente nelas e então está simplesmente exercitando seu direito à liberdade de expressão. Mesmo quando essas declarações podem promover um clima de ódio contra alguns setores da população.

Por outro lado, o filme alude ao risco de que uma decisão a favor de Lipstadt desse a Irving uma medalha de honra ou o convertesse em um mártir da liberdade de expressão ${ }^{5}$. Isso fica claro nas cenas que precedem e seguem ao pronunciamento da sentença em favor de Lipstadt.

Um setor majoritário da doutrina europeia propõe mitigar esses riscos com uma intervenção estatal mínima na regulação da memória. Por exemplo, essa doutrina alerta contra a criminalização do negacionismo, favorecendo o debate público como um meio de refutar a negação de fatos históricos. A mesma Deborah E. Lipstadt, alguns anos após os eventos representados no

\footnotetext{
${ }^{3}$ No direito penal, as sentenças firmes (ou transitadas em julgado), que já não podem ser revistas por tribunais de hierarquia superior, esclarecem de maneira final se o acusado é culpado ou não. Desta maneira, se garante ao acusado (e à sociedade) que não se encontre em uma situação de incerteza a respeito da justiça, o que poderia vulnerabilizar o seu direito a um processo justo.

4 Veja também os chamados pela liberdade de pesquisa histórica lançados por historiadores italianos em 2006, Libertà per la storia, disponível em: < http://www.italia-resistenza.it> (acesso em 23 de julho de 2020); e historiadores franceses em 2005, Liberté pour l'Histoire, disponível em: http://www.lph-asso.fr (acesso em 23 de julho de 2020).

${ }^{5} \mathrm{~A}$ respeito da polarização ideológica sobre David Irving, veja, por exemplo, o editorial de Christopher Histchens, 'The Strange Case of David Irving' (20 de mayo de 2001) no Los Angeles Times. Disponivel em: $<$ https://www.latimes.com/archives/la-xpm-2001-may-20-bk-144-story.html>. Acessado em 23 de julho de 2020.
} 
filme e no âmbito de um processo criminal por negacionismo contra Irving na Suíça, comentou que ele deveria ser deixado em liberdade e que não se sentia à vontade para impor sanções penais à opinião ${ }^{6}$. Cabe mencionar que essa resistência ao direito penal como instrumento para tutelar a memória, que se encontra também na jurisprudência do Tribunal Europeu Para os Direitos Humanos $^{7}$, diminui quando o objeto de negação é o Holocausto ${ }^{8}$. Além disso, se justifica e ratifica a nível normativo a intervenção do direito penal em casos de "apologia pública, (...) negação ou (...) banalização flagrante dos crimes de genocídio, crimes contra a humanidade e crimes de guerra conforme definidos nos artigos 6,7 e 8 do Estatuto do Tribunal Penal Internacional" quando possa incitar o ódio e a violência?.

Agora bem, se esse marco conceitual pode funcionar em países onde a emergência democrática é relativamente limitada e o debate público é geralmente fomentado, podemos ter certeza de que pode ser eficaz mesmo em países caracterizados por profundos conflitos sociais, violência e marginalização?

No Brasil, a negação dos crimes da ditadura civil-militar e empresarial (ou até mesmo da caracterização da ruptura institucional e da ordem democrática ocorrida entre 1964 e 1985 como período ditatorial) tem marcado a história recente do país, possibilitando que, em plena pandemia, deputados federais participem da organização de atos políticos públicos reivindicando o fechamento do Supremo Tribunal Federal ${ }^{10}$ e a volta do Ato Institucional No 5 - AI- $5^{11}$, que resultou na suspensão dos direitos políticos dos cidadãos contrários ao regime, no fechamento do Congresso Nacional e de Assembleias Legislativas, intervenções federais nos estados e municípios, na suspensão das garantias constitucionais (como, por exemplo, o Habeas Corpus), na censura prévia às artes e à imprensa e demissões sumárias no serviço público, dentre outras consequências. Na prática, o AI-5 organizou o aparato de repressão e institucionalizou a tortura como forma de obtenção de informação.

A negação de caracterização do regime instaurado em 1964 como ditadura está presente nos quarteis desde os tempos de arbítrio, dando origem à narrativa institucional de que o que houve foi uma "revolução" para salvaguarda da ordem ${ }^{12}$. Este discurso, para além de disputar a memória coletiva e a narrativa institucional acerca do período, visa defender a adoção de medidas

6 Brendan O'Neill, "'Irving? Let the guy go home"' (4 de janeiro de 2006). Disponível em: <http://news.bbc.co.uk/2/hi/uk_news/4578534.stm>. Acesssado em 23 de julho 2020.

7 En particular, ver o caso Perinçek c. Suiza (Demanda no. 27510/08) Sentença da Grande Sala do TEDH de 15 de outubro de 2015; para una resenha da jurisprudência do TEDH, ver LoBBA, Paolo. Holocaust Denial before the European Court of Human Rights: Evolution of an Exceptional Regime. European Journal of International Law, 2015, 26, 1, 237-253.

8 DANIELE, Luigi. Negazionismo e libertá di espressione: dalla sentenza Perinçek c. Svizzera alla nuova aggravante prevista nell'ordinamento italiano: Per una democracia tolerante anziché "militante". Diritto Penale Contemporáneo, 2017. Disponível em: <https://archiviodpc.dirittopenaleuomo.org/upload/4311daniele1017.pdf>. Acesso em 23 de julho de 2020.

9 Artigo 1(1)(c) da Decisão Marco 2008/913/GAl do Conselho da União Europeia de 28 de novembro de 2008 , relativa à luta contra determinadas formas e manifestações de racismo e xenofobia mediante 0 Direito Penal.

10Alexandre Autoriza abertura de inquérito para investigar atos em favor do Al-5. Disponível em: <https://www.conjur.com.br/2020-abr-21/ministro-autoriza-investigacao-atos-pro-golpe-favor-ai>. Acessado em 26 de julho de 2020.

11 Disponível em: < http://www.planalto.gov.br/ccivil_03/ait/ait-05-68.htm>. Acessado em 26 de julho de 2020.

12 LIBÓRIO, Bárbara. De 1964 aos dias atuais: nos reservados círculos militares, o golpe nunca deixou de ser comemorado. Disponível em: < https://epoca.globo.com/de-1964-aos-dias-atuais-nos-reservadoscirculos-militares-golpe-nunca-deixou-de-ser-comemorado-23555401>. Acessado em 26 de julho de 2020. 
antidemocráticas na área de segurança pública, como o uso da violência física em protestos massivos contrários ao governo, mobilizando um discurso de guerra civil em curso e uma suposta nova necessidade de salvaguarda da lei e da ordem ${ }^{13}$.

Vale ressaltar que, em seu relatório publicado em dezembro de 2014, a Comissão Nacional da Verdade, criada pela Lei 12.528/11, reconheceu um total de 434 pessoas desaparecidas forçadamente a partir da intervenção estatal no período compreendido entre 1946 e $1988^{14}$, que envolve a duração dos tempos ditatoriais. Ademais, as principais técnicas de tortura utilizadas na última ditadura brasileira foram documentadas pelo Projeto Brasil: Nunca Mais, coordenado por Don Paulo Evaristo Arns, ainda durante a redemocratização do país.

O negacionismo quanto aos crimes da ditadura civil-militar tem paralelo direto com o negacionismo praticado por Irving. O filme retrata o argumento basilar para absolvição dos réus, aceitando a tese de defesa da justificação das acusações feitas por Lipstadt em seu livro, pois o juízo entendeu que

A falsificação dos registros históricos foi deliberada e que Irving foi motivado por um desejo de apresentar eventos de uma forma consistente com suas próprias crenças ideológicas, mesmo que isso envolvesse distorção e manipulação de evidências históricas.

É possível, pois, compreender os paralelos entre as bases do negacionismo da ocorrência do Holocausto e do negacionismo dos crimes da ditadura civil-militar: ambos ancoram-se na manipulação da história para justificar e perpetuar crenças ideológicas não compatíveis com o regime democrático e de promoção de direitos.

\section{REFERÊNCIAS}

ARNS, Paulo Evaristo. Brasil: nunca mais. Vozes, 1985.

BRASIL. Comissão Nacional da Verdade. Mortos e desaparecidos políticos / Comissão Nacional da Verdade. Brasília: CNV, 2014.

DANIELE, Luigi. Negazionismo e libertá di espressione: dalla sentenza Perinçek c. Svizzera alla nuova aggravante prevista nell'ordinamento italiano: Per una democracia tolerante anziché "militante". Diritto Penale Contemporáneo, 2017. Disponivel em: <https://archiviodpc.dirittopenaleuo mo.org/upload/4311-daniele1017.pdf>. Acesso em 23 de julho de 2020.

FLORES, Marcello. Revisionismo storiografico. Enciclopedia Italiana, 2007, Apêndice VII. Disponível em: <http://www.treccani.it/enciclopedia/revisionismo-storiografico_(Enciclopedia-Italia na)/>; Acesso em 23 de julho de 2020.

FRONZA, Emanuela; GAMBERINI, Alssandro. Le ragioni che contrastano l'introduzione del negazionismo come reato. Diritto Penale Contemporaneo, 29 de octubre de 2013, p. 5.

LOBBA, Paolo. Holocaust Denial before the European Court of Human Rights: Evolution of an Exceptional Regime. European Journal of International Law, 2015, 26, 1, 237-253.

VIDAL-NAQUET, Pierre. Les Assassins de la Mémoire. "Un Eichmann de Papier" et autres essais sur le révisionnisme. Paris: Seuil, 1995;

13 Eduardo Bolsonaro fala em novo Al-5 "se esquerda radicalizar". Disponível em: <https://noticias.uol.com.br/politica/ultimas-noticias/2019/10/31/eduardo-bolsonaro-fala-em-novo-ai5-se-esquerda-radicalizar.htm?cmpid=copiaecola>. Acessado em 26 de julho de 2020.

14 BRASIL. Comissão Nacional da Verdade. Disponível em: < http://cnv.memoriasreveladas.gov.br/images/ pdf/relatorio/volume 3 digital.pdf>. Acesso em 26 de julho e 2020. 